\title{
Synergistic antitumor activity of the CD122-biased immunostimulatory cytokine NKTR-214 when combined with anti-PD-1 in murine tumor models
}

\author{
Addepalli Murali ${ }^{1}$, John L Langowski ${ }^{2 *}$, Pena Rhoneil ${ }^{2}$, Priyam Jha', Deborah H Charych², Stephen K Doberstein², \\ Ute Hoch ${ }^{2}$
}

From 30th Annual Meeting and Associated Programs of the Society for Immunotherapy of Cancer

(SITC 2015)

National Harbor, MD, USA. 4-8 November 2015

\section{Background}

NKTR-214 is an immunotherapeutic drug that exerts its biological activity by binding and activating the interleukin-2 (IL-2) receptor beta subunit (IL-2Rb), thereby causing expansion of memory effector $\mathrm{T}$ cells in the tumor. NKTR-214 consists of 4-6 releasable polyethylene glycol (PEG) chains conjugated to IL-2 at a defined region within the protein. In vivo, some of these PEG chains slowly release to generate active IL-2 conjugates. The location of these PEG chains on IL-2 interferes with its interaction on the IL-2 receptor alpha (IL-2Ra), responsible for activating undesirable Treg cells in tumor. In vivo, the receptor bias markedly increases the ratio of tumor killing CD8 T cells to Treg cells in tumors, while simultaneously leading to high and sustained tumor exposure. NKTR-214 showed marked single agent efficacy in aggressive murine tumors, and synergy with anti-CTLA-4, producing durable responses. Here, we examine the efficacy and mechanism of NKTR-214 combined with anti-PD-1 in murine tumor models.

\section{Methods}

Mice bearing subcutaneous CT26 colon, EMT6 mammary, or LLC Lewis Lung carcinoma tumors were treated with NKTR-214 i.v. every nine days (three administrations), murine anti-PD-1 twice-weekly for three weeks, or both in combination. Efficacy was determined based on tumor growth inhibition relative to vehicle (TGI), long-term tumor growth delay measured by time to reach $4 \mathrm{x}$ initial

${ }^{2}$ Nektar Therapeutics, San Francisco, CA, USA

Full list of author information is available at the end of the article tumor volume (Tumor Volume Quadrupling Time, TVQT), and number of long term tumor-free animals.

\section{Results}

In the CT26 model, single agent NKTR-214 led to greater TGI (66\%) at day 11 than anti-PD-1 alone (37\%). The combination proved synergistic with $9 / 10$ animals tumorfree 100 days after dosing initiation. The EMT6 model proved more resistant to single-agent therapy, with NKTR-214 yielding $42 \%$ TGI at day 17 . While TGI was not enhanced by addition of anti-PD-1, TVQT was increased to 29.6 days relative to single agent NKTR-214 (16.7) and vehicle (10.9), with $4 / 10$ tumor free animals 73 days after dosing initiation. Finally, the LLC model proved sensitive to NKTR-214 single agent, with a 59\% TGI at day 11 and 2/10 animals tumor free, while antiPD-1 alone was not active. The combination of the two agents increased TVQT (20 days) compared to NKTR-214 alone (14), anti-PD1 alone (8) and vehicle (7), and increased tumor-free animals (4/10) relative to NKTR-214 $(2 / 10)$ and anti-PD1 (1/10) alone.

\section{Conclusions}

NKTR-214 provides an antibody-like dosing regimen and complementary mechanism of action to checkpoint inhibition. The synergy observed in mouse models holds promise for durable responses in humans.

\footnotetext{
Authors' details

${ }^{1}$ Nektar Therapeutics, Hyderabad, India. ${ }^{2}$ Nektar Therapeutics, San Francisco, CA, USA.
} 
doi:10.1186/2051-1426-3-S2-P231

Cite this article as: Murali et al:: Synergistic antitumor activity of the

CD122-biased immunostimulatory cytokine NKTR-214 when combined with anti-PD-1 in murine tumor models. Journal for ImmunoTherapy of Cancer 2015 3(Suppl 2):P231.

Submit your next manuscript to BioMed Central and take full advantage of:

- Convenient online submission

- Thorough peer review

- No space constraints or color figure charges

- Immediate publication on acceptance

- Inclusion in PubMed, CAS, Scopus and Google Scholar

- Research which is freely available for redistribution

Submit your manuscript at www.biomedcentral.com/submit
C Biomed Central 